\title{
Coordinated Contract Design for Two-Level Supply Chain Considering Supplier's Quality Level
}

\author{
Pin Zhuang \\ College of Economics and Management \\ Nanjing University of Aeronautics and Astronautics \\ Nanjing 210016, China \\ zpnuaa@163.com
}

\begin{abstract}
This paper investigated procurement contracts in a two-level supply chain system which includes a supplier and a manufacturer who sells the supplier's product to the final market and the market demand function was given by linear demand function in quality and price. We designed three supply chain contract models employing game theory: optimal contracts in centralized control setting, profit margin contract and profit sharing contract in decentralized control setting. The study shows that the profit sharing contract could achieve supply chain channel coordination in decentralized setting, besides, the retail price is decreasing function with supplier's quality level, and meanwhile the order quantity and the expected profit are increasing functions with supplier's quality level.
\end{abstract}

Keywords-supply chain contract; game theory; supplier's quality; channel coordination

\section{INTRODUCTION}

Nowadays, the distance from producer to consumer has increased as a result of globalization in supply chain. Therefore, keeping good quality along the supply chain has become a significant challenge. Today more than ever, final product quality is highly dependent upon a company's supplier product quality.

Supplier quality management (SQM) is considered as a proactive approach in the buyers' perspective to seek for continuous supply quality improvement and collaborative ongoing alliance between buyers and suppliers. The success of an SQM framework involves the orchestration of supplier alliances, supplier development, and supplier monitoring within a globally scalable, secure supplier network (I-Ki, Chin, 2004[1]).

Supplier quality management is commonly used in conjunction with other monitoring efforts, particularly in aerospace, auto manufacturing, and food industries. Complex manufacturing depends heavily on tracking to reduce process variation, cycle time, and risk. These three factors are essential to compliance and quality management objectives. The passage of AS9100 Rev. C requirements defining traceability, document control, and record storage has increased the importance of SQM. Suppliers are subject to continuous monitoring in order to retain approval status (e.g., Boeing Company, Airbus Group, LMI Aerospace, CPI Aero).

Agrawal and Muthulingam (2015) investigated how the depreciation of organizational knowledge (organizational forgetting) affects quality performance[2]. Yan X. H., Zhao H. and Tang $\mathrm{K}(2015)$ analyzed the first-mover right in quality contracting by considering two different strategies for the buyer: the quality requirement strategy $(\mathrm{QR})$ and quality promise strategy (QP) [3]. Liu and Wang (2015) developed a quality control game model for logistic CS service supply chain and analyzed the impact of different risk attitude of a logistics service integrator and a functional logistics service provider[4]. Ma P., Wang H.Y.and Shang J.F(2013) investigated the issue of channel coordination for a two-stage supply chain with one retailer and one manufacturer. They identified the optimal level of retail sales effort, optimal level of quality-improvement effort and optimal supply chain profit[5]. Dai Y., Zhou S. $\mathrm{X}$.and Xu Y.(2012) developed a single-period model with a supplier that provides a product to an original equipment manufacturer, which in turn sells it to customers, customer demand is random and affected by the length of the product warranty period. They analyze two different scenarios based on which party sets the warranty period: manufacturer warranty and supplier warranty. Product quality is controlled by the supplier, and the manufacturer determines the ordering quantity[6].

Supply chain contracts are considered as a useful tool to structure the costs and rewards of all of its members so as to achieve coordination in a decentralized situation. Zhang W. Zhou D. and Liu L.W(2014) analyzed and compared five contract schemes used in a supply chain: fixed price (FP), cost reimbursement $(\mathrm{CR})$, procurement control $(\mathrm{PC})$, index-linked payment (IL), and relational (RL) contracts[7]. Kolay and Shaffer (2013) Studied quantity discounts and two-part tariffs when an upstream firm sold its product in a downstream market[8].

\section{Coordination Mechanisms in Centralized Control SETTING}

We consider the standard setting with a single supplier and single manufacturer who sells the supplier's product to the final market. Manufacturer orders from supplier according to market demand $D$. The situation is described as follows. The market demand function is given by linear demand function in quality and price: $D(p, x)=\alpha-\beta p+\varepsilon x$, where $\alpha>0, \beta>0$ and $\varepsilon>0$ are known parameters. The supplier's production cost is given by $s \equiv S(q, x)=(\lambda+\delta x) q+\phi x^{2} / 2$, the supplier's variable cost is $\lambda+\delta x, \lambda$ denotes the variable production cost per unit 
not including the quality related costs, the unit variable cost increases (decreases) by $|\delta x|$. The supplier's fixed production cost is $\phi x^{2} / 2$.

The manufacturer's internal variable costs are $m$, the wholesale price is $w$, and the retail price selling to the customer is $p$. The manufacturer's order quantity is $Q$, without loss of generality, we assume that the supplier follows a lot-forlot policy, i.e., the supplier's production lot size is equal to the lot size shipped to the manufacturer. Let $\pi$ and $\Pi$ denote the profit and the expected profit respectively.

We first investigate the centralized situation where one central decision maker seeks to maximize total system profits. Then the supply chain system profit can be written as

$\Pi(p)=D(p-\lambda-\delta x-m)$. From the first optimal condition $\partial \Pi(p) / \partial p=0$, we obtain Lemmal.

Lemma1. The optimal contract in centralized control setting under asymmetric supplier quality information is following.

The optimal retail price is

$$
P^{c}=\frac{\alpha+\beta(\lambda+m)+(\varepsilon+\beta \delta) x}{2 \beta}
$$

The optimal order quantity is

$$
Q^{c}=\frac{\alpha-\beta(\lambda+m)+(\varepsilon-\beta \delta) x}{2}
$$

Therefore, the maximum supply chain expected profit is given by

$$
\Pi^{c}=\frac{[\alpha-\beta(\lambda+m)+(\varepsilon-\beta \delta) x]^{2}}{4 \beta}
$$

\section{CoORdinAtion Mechanisms In DeCEnTRALIZEd Control SETTING}

\section{A. Profit Margin Contract (no coordination situation)}

Just as a dominated supplier will declare a unit wholesale price $w$, the economics and marketing literature has long recognized that a dominated manufacturer can declare a required profit margin. The manufacturer's profit function can be written as: $\Pi_{m}=Q(p-w-m)$. After the dominant manufacturer declares his required profit margin $M$, i.e., $M=\Pi_{m} / Q$, the supplier knows that, for whatever she quotes, the unit retailer price will be $p=w+m+M$. Hence, the supplier's profit function is $\Pi_{s}(w, x)=[\alpha-\beta(w+m+M)+\varepsilon x](w-\lambda-\delta x) \quad$. From the first optimal condition $\partial \Pi_{s}(w, x) / \partial w=0, \partial \Pi_{s}(w, x) / \partial x=0$ we obtain the optimal wholesale price $w(M)=[\alpha+\beta(\lambda-m-M)+(\varepsilon+\beta \delta) x] /(2 \beta)$ $x(M)=\frac{\beta \delta(m+M)-(\alpha \delta+\lambda \varepsilon)+(\varepsilon+\beta \delta) w}{2 \varepsilon \delta+\phi}$
Substituting $_{w(M)}$ into the manufacturer's expected profit function $\Pi_{m}(M)$, solving $\partial \Pi_{m}(M) / \partial M=0$, we obtain optimal profit margin $M^{d}$. By calculating the above function, we can derive Lemma 1.

Lemma1. The profit margin contract in decentralized control setting is following.

The optimal profit margin is

$$
M^{d}=\frac{\alpha-\beta(\lambda+m)+(\varepsilon-\beta \delta) x}{2 \beta}
$$

The optimal wholesale price is

$$
W^{d}=\frac{\alpha+\beta(3 \lambda-m)+(\varepsilon+3 \beta \delta) x}{4 \beta}
$$

The optimal retail price is:

$$
P^{d}=\frac{3 \alpha+\beta(\lambda+m)+(3 \varepsilon+\beta \delta) x}{4 \beta}
$$

The optimal order quantity is:

$$
Q^{d}=\frac{\alpha-\beta(\lambda+m)+(\varepsilon-\beta \delta) x}{4}
$$

The manufacturer's expected profit is:

$$
\Pi_{m}^{d}=\frac{[\alpha-\beta(\lambda+m)+(\varepsilon-\beta \delta) x]^{2}}{8 \beta}
$$

The supplier's expected profit is:

$$
\Pi_{s}^{d}=\frac{[\alpha-\beta(\lambda+m)+(\varepsilon-\beta \delta) x]^{2}}{16 \beta}
$$

The supply chain system's expected profit is:

$$
\Pi^{d}=\frac{3[\alpha-\beta(\lambda+m)+(\varepsilon-\beta \delta) x]^{2}}{16 \beta}
$$

By calculating, we can obtain $\Pi^{d}<\Pi^{c}$, so supply chain don't achieve coordination in profit margin contract.

\section{B. Profit Sharing Contract (coordination situation)}

We now design a profit sharing contract to coordinate the supply chain. Under the profit sharing contract, let $\psi$ be the fraction of channel expected profit the retailer keeps, $\psi \in[0,1]$, so $1-\psi$ is the fraction the supplier earns. The manufacturer's expected profit is $\Pi_{m}^{p}=\psi \Pi^{p}$, and the supplier's expected profit is $\Pi_{s}^{p}=(1-\psi) \Pi^{p}$. With coordination, the system expected profit is $\Pi^{p}=\Pi^{c}$, the optimal order quantity is $Q^{p}=Q^{c}$, and the optimal retail price is $P^{p}=P^{c}$. 
The buyer's expected profit function can be written as $\Pi_{m}^{p}=E[Q \bullet M]$, it also can be written as $\Pi_{m}^{p}=E\left[Q^{c} \bullet M\right]=\psi \Pi^{c}$. By calculating the above function, we can derive Lemma2.

Lemma2. The profit sharing contract in decentralized control setting is following.

The optimal profit margin is

$$
M^{p}=\frac{\psi[\alpha-\beta(\lambda+m)+(\varepsilon-\beta \delta) x]}{2 \beta}
$$

The optimal wholesale price is

$$
W^{p}=\frac{(2-\psi)(\alpha-\beta m)+(2+\psi) \beta \lambda}{4 \beta}+\frac{[(2-\psi) \varepsilon+(2+\psi) \beta \delta] x}{4 \beta}
$$

The optimal retail price is:

$$
P^{p}=\frac{\alpha+\beta(\lambda+m)+(\varepsilon+\beta \delta) x}{2 \beta}
$$

The optimal order quantity is:

$$
Q^{p}=\frac{\alpha-\beta(\lambda+m)+(\varepsilon-\beta \delta) x}{2}
$$

The manufacturer's expected profit is:

$\Pi_{m}^{p}=\frac{\psi[\alpha-\beta(\lambda+m)+(\varepsilon-\beta \delta) x]^{2}}{4 \beta}$

The supplier's expected profit is:

$$
\Pi_{s}^{p}=\frac{(1-\psi)[\alpha-\beta(\lambda+m)+(\varepsilon-\beta \delta) x]^{2}}{4 \beta}
$$

The supply chain system's expected profit is:

$$
\Pi^{p}=\frac{[\alpha-\beta(\lambda+m)+(\varepsilon-\beta \delta) x]^{2}}{4 \beta}
$$

\section{RESUlTS}

In this section, we give several numerical examples to analyze the effects of the supplier quality level on the retail price, the order quantity and supply chain system's expected profit. Let $\alpha=30, \beta=3, \varepsilon=100, \lambda=3, \delta=1.5, m=5$. We assume the quality conform rate of $x$ varies from 0.5 to 1 .

\section{A. Impact on optimal retail price}

Fig.1 illustrates the impact of varying $x$ on the optimal retail price. From this figure, we can see that optimal retail price is a linearly decreasing function of $x$.

Comparing the optimal retail price in profit margin contract and profit sharing contract in decentralized control setting in Fig.1, the latter is less than the former. This implies that latter is a more optimal and adaptable instrument for channel coordination.

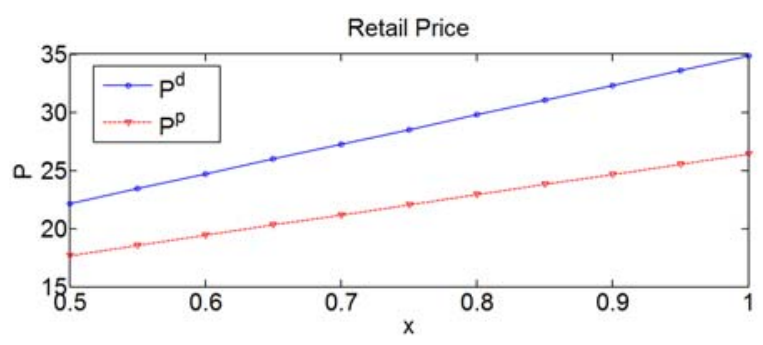

Fig. 1. $X$ versus optimal order quantity

\section{B. Impact on optimal order quantity}

Fig.2 illustrates the impact of varying $x$ on the optimal order quantity. From this figure, we can see that optimal order quantity is a linearly increasing function of $x$.

Comparing the optimal order quantity in profit margin contract and profit sharing contract in decentralized control setting in Fig.2, the latter is more than the former. This implies that latter is a more optimal and adaptable instrument for channel coordination.

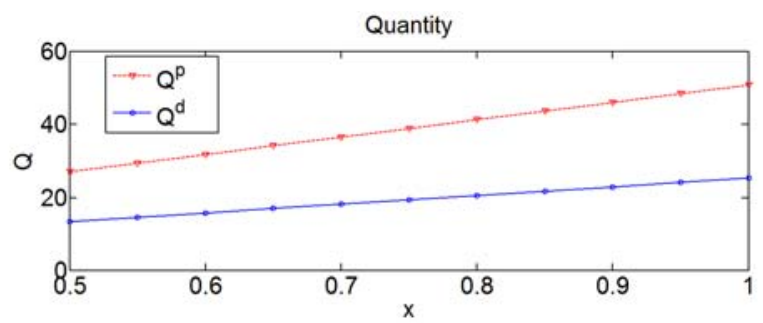

Fig. 2. $X$ versus optimal order quantity

\section{Impact on system's expected profit}

Fig.3 illustrates the impact of varying $x$ on the supply chain system's expected profit. From this figure, we can see that the system's expected profit is a non-linearly increasing function of $x$.

Comparing the system's expected profit in profit margin contract and profit sharing contract in decentralized control setting in Fig.3, the latter is more than the former. This implies that latter is a more optimal and adaptable instrument for channel coordination.

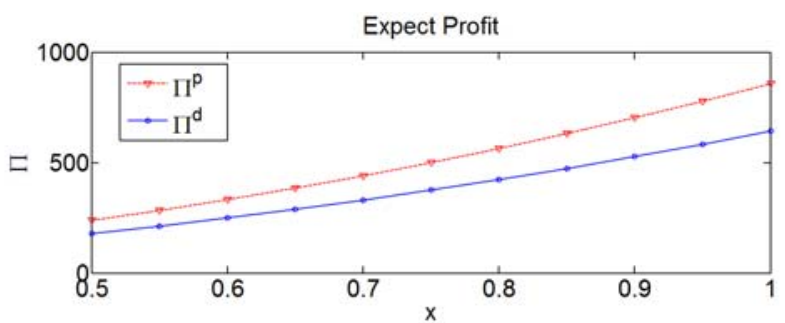

Fig. 3. $X$ versus system's expected profit 


\section{CONCLUSION}

In this paper, we investigated a two-level supply chain system that includes a manufacturer and a supplier considering the supplier's quality. We designed three supply chain contract models employing game theory: optimal contracts in centralized control setting, profit margin contract and profit sharing contract in decentralized control setting.

Finally, we used several mathematical simulation cases to analyze above contract models, we can draw a conclusion that the profit sharing contract could achieve supply chain channel coordination in decentralized setting, besides, the retail price is decreasing function with supplier's quality level, and meanwhile the order quantity and the expected profit are increasing functions with supplier's quality level.

\section{REFERENCES}

[1] I-Ki, Y., \& Kwai-Sang Chin. (2004). Critical success factors of supplier quality management. Asian Journal on Quality, 5(1), 85-109.
[2] Agrawal A., Muthulingam S. (2015), Does a Procurement Service Provider Generate Value for the Buyer Through Information About Supply Risks, Manufacturing \& Service Operations Management, Articles in Advance, 1-18

[3] Yan X. H., Zhao H., Tang K.(2015) Requirement or Promise? An analysis of the first-Mover advantage in quality contracting. Production and Operations Management, articles in advance, pp.1-17

[4] Liu W.H., Wang Y.J. (2015). Quality control game model in logistics service supply chain based on different combinations of risk attitude. Int. J. Production Economics, 2015, 161, 181-191

[5] Ma P., Wang H.Y., Shang J.F (2013). Contract design for two-stage supply chain coordination: Integrating manufacturer-quality and retailermarketing efforts. International Journal of Production Economics, 146(2), 745-755.

[6] Dai Y., Zhou S. X., Xu Y.(2012). Competitive and collaborative quality and warranty management in supply chain. Production and Operations Management, 21(1), 129-144

[7] Zhang W. Zhou D., Liu L.W.(2014) contracts for changing times: sourcing with raw material price volatility and information asymmetry, Manufacturing Service Oper. Management, 16(1):133-148

[8] Kolay S., Shaffer G(2013). Contract Design with a Dominant Retailer and a Competitive Fringe. Management Science, 59(9),2111-2116 